\title{
Mental rubbernecking to negative information depends on task context
}

\author{
MARCIA K. JOHNSON, KAREN J. MITCHELL, CAROL L. RAYE, \\ JOSEPH T. MCGUIRE, and CHARLES A. SANISLOW \\ Yale University, New Haven, Connecticut
}

\begin{abstract}
We previously demonstrated mental rubbernecking during the simple cognitive act of refreshing a just activated representation. Participants saw two neutral and one negative word presented simultaneously and, $425 \mathrm{msec}$ later, were cued to mentally refresh (i.e., think of) one of the no-longer-present words. They were slower to refresh a neutral word than the negative word (Johnson et al., 2005, Experiment 6A). The present experiments extended that work by showing mental rubbernecking when negative items were sometimes the target of refreshing, but not when negative items were present but never the target of refreshing, indicating that expectations influence mental rubbernecking. How expectations might modulate the impact of emotional distraction is discussed.
\end{abstract}

Cognitive, social, and clinical researchers have converging interests in understanding how emotion affects cognition (e.g., Christianson, 1992; Erdelyi, 1974; Mathews \& MacLeod, 1994; Niedenthal \& Kitayama, 1994; Reisberg \& Hertel, 2004). Key questions include the following: In comparison with neutral stimuli, are emotional stimuli privileged in processing, more disruptive of ongoing processing of other information, or less subject to context effects or cognitive control? Such questions can be posed for many types and/or phases of processing: perceptual processes, such as locating or identifying stimuli (e.g., Koster, Crombez, Verschuere, \& De Houwer, 2004; Most, Chun, Widders, \& Zald, 2005); postperceptual reflective processes, such as refreshing or rehearsing information that is still active (e.g., Johnson et al., 2005; Mather et al., 2006); other reflective processes (e.g., reactivating, retrieving, noting relations) that serve to strengthen, elaborate, and organize items from an informational stream, such as a list or a story (Burke, Heuer, \& Reisberg, 1992; Kensinger, Anderson, Growdon, \& Corkin, 2004; Kensinger \& Corkin, 2003), or events from one's life (Nolen-Hoeksema, 2000); and consolidation processes that might be initiated by any of these component cognitive processes (Cahill et al., 1996; Hamann, 2001; LaBar \& Phelps, 1998).

For example, in one recent study, Most et al. (2005) presented participants with pictures in a rapid sequence (100 msec per picture) and found that an emotional picture disrupted detection of a target picture presented $200 \mathrm{msec}$,

This research was supported by Grant AG15793 from the National Institute on Aging and by Grant MH 62196 from the National Institute of Health. We thank Jessica Jacobson and Kristen Pring-Mill for assistance in testing participants and scoring data for Experiment 1B. Correspondence concerning this article should be addressed to M. K. Johnson, Department of Psychology, Yale University, P.O. Box 208205, New Haven, CT 06520-8205 (e-mail: marcia.johnson@yale.edu). but not $800 \mathrm{msec}$, after it. Such a pattern indicates that the distracting impact of emotion operates on early perceptual/ attentional processes. Evidence from many studies suggests that emotion also has an impact on postperceptual, reflective processes. For example, emotional information is often remembered better than neutral information, even when orienting tasks ensure the perceptual processing of all stimuli (e.g., Burke et al., 1992; Kensinger \& Corkin, 2003; Strange, Hurlemann, \& Dolan, 2003). Nevertheless, as was noted by Kensinger and Corkin, the relative impact of emotion on different specific component cognitive processes is hard to identify with complex tasks or materials. For example, sometimes emotion facilitates (e.g., Doerksen \& Shimamura, 2001) and sometimes it disrupts (Johnson, Nolde, \& De Leonardis, 1996; Mather et al., 2006) source memory. Resolving such inconsistencies in findings and, perhaps, better understanding individual or group differences in the impact of emotion on cognition may depend on specifying the particular processes engaged in any given task (e.g., Gotlib et al., 2004; Johnson et al., 1996).

In order to clarify how emotion might affect reflective processes, here we will consider the impact of negative emotion on one of the simplest postperceptual, reflective processes: refreshing - that is, briefly thinking back to a just-activated thought or percept (Johnson, Reeder, Raye, \& Mitchell, 2002; Raye, Johnson, Mitchell, Reeder, \& Greene, 2002). Refreshing is initiated while a representation is active and has the effect of selectively increasing or prolonging activation of information (e.g., Johnson \& Hirst, 1993) that would otherwise quickly become less available (e.g., Sperling, 1960). Refreshing foregrounds the refreshed information and is an example of top-down control over thought - a basic process of executive function (Raye, Johnson, Mitchell, Greene, \& Johnson, in press). Being able to selectively refresh one of several active representations specified by an agenda is one critical 
example of cognitive control. Selective refreshing is associated with activity in the dorsolateral prefrontal and anterior cingulate cortex (Johnson et al., 2005, Experiment 5) - components of a network thought to underlie cognitive control (Botvinick, Braver, Barch, Carter, \& Cohen, 2001).

The conditions under which refreshing occurs during ongoing cognition vary in amount of distraction or competition among candidates; not all active representations are equally salient. Thus, refreshing a representation under different conditions should vary in the amount of control required. We recently reported evidence for the disruption of the refreshing of a neutral item by emotionally salient distraction (Johnson et al., 2005, Experiment 6A). Participants read three words aloud (all neutral or two neutral and one negative), and then either one of the words was re-presented and read aloud again or the participants were cued to think of (refresh) and say one of the words. As indexed by longer response times (RTs), refreshing a neutral item from a set including a negative item required greater cognitive control than did refreshing the negative item or refreshing a neutral item from a set including only neutral items (see the top of Table 1).

These results could indicate that negative emotion automatically disrupts reflective processes, such as refreshing. However, the negative items may have been especially potent distractors during refreshing because they were task relevant; that is, emotional items were targets of refreshing on some trials. Here, we asked whether an emotionally salient negative item that is perceived and, thus, presumably active will still delay refreshing a neutral item even if emotional items are never a target of refreshing. Does the simple presence of a negative item in the set of activated representations automatically disrupt the refreshing of a

Table 1

Mean Response Times (in Milliseconds, With Standard Errors of the Means) for Johnson et al. (2005, Experiment 6A) and Experiments $1 \mathrm{~A}$ and $1 \mathrm{~B}$

\begin{tabular}{|c|c|c|c|c|}
\hline \multirow[b]{2}{*}{ Condition } & \multicolumn{2}{|c|}{ Refresh } & \multicolumn{2}{|c|}{ Repeat } \\
\hline & $M$ & SEM & $M$ & SEM \\
\hline \multicolumn{5}{|c|}{ Johnson et al. (2005, Experiment 6A) } \\
\hline NNN_N & $618^{\S}$ & 18 & 503 & 12 \\
\hline ENN_E & $604^{\dagger}$ & 18 & 507 & 13 \\
\hline ENN_N & $652^{\dagger \S}$ & 18 & 512 & 11 \\
\hline \multicolumn{5}{|c|}{ Experiment 1A } \\
\hline ENN_E & $649^{\dagger}$ & 17 & 525 & 10 \\
\hline ENN_N & $691^{\dagger}$ & 12 & 527 & 9 \\
\hline \multicolumn{5}{|c|}{ Experiment 1B } \\
\hline \multicolumn{5}{|l|}{ Group 1} \\
\hline NNN_N & 622 & 17 & 507 & 13 \\
\hline ENN_N (50\% E) & 621 & 18 & 509 & 13 \\
\hline \multicolumn{5}{|l|}{ Group 2} \\
\hline ENN_N (100\% E) & 642 & 22 & 512 & 11 \\
\hline
\end{tabular}

Note-Within an experiment, means with the same superscript are significantly different $(p<.01)$. E, emotional/negative word; $\mathrm{N}$, neutral word. The first three letters (before the underscore) indicate the composition of the initial set of words to be read; the last letter (after the underscore) indicates the nature of the critical (repeated or refreshed) word. neutral item, or does the impact of negative information vary with the likelihood that the task agenda encompasses negative information? We used the same task as that in Johnson et al. (2005, Experiment 6A) but varied whether the participants were sometimes (Experiment 1A) or never (Experiment 1B) cued to refresh emotional items. The outcome should provide evidence about the degree to which the impact of negative emotion on refreshing can be modulated by expectations.

It should be noted that negative and positive stimuli do not always produce parallel effects (e.g., McKenna \& Sharma, 2004). We initially focused on the impact of negative information on refreshing because the potential impact of negative stimuli on cognition has featured prominently in discussions of emotion dysregulation - for example, in anxiety and depression (e.g., Gotlib et al., 2004; Nolen-Hoeksema, 2000). A logical next step, if we found that task context modulates the impact of negative emotional stimuli on refreshing in healthy young adults, would be to determine whether it similarly modulates the impact of emotion in individuals with emotion regulation deficits.

\section{METHOD}

\section{Participants}

College students participated for either course credit or a small monetary payment (Experiment $1 \mathrm{~A}, n=24$ [15 females], $M$ age $=$ 20.4 years, range $=18-26$ years; Experiment $1 \mathrm{~B}$, Group $1, n=30$ [16 females], $M$ age $=19.2$ years, range $=18-22$ years; Group 2, $n=20$ [13 females], $M$ age $=19.6$ years, range $=18-29$ years $)$.

\section{Materials}

The materials for each experiment were a subset of those used in Johnson et al. (2005, Experiment 6A). All negative emotional words (e.g., slime, morgue, and divorce) and most neutral words (e.g., silk, engine, and nature) were taken from Bellezza, Greenwald, and Banaji (1986). Emotion ratings were calculated by multiplying Bellezza et al.'s emotion rating and pleasantness rating (reversing the pleasantness score). The 108 negative emotional words used ranged from 18.21 to $36.44(M=25.31, S E=0.45)$, and the 216 neutral words used ranged from 1.54 to $9.74(M=5.08, S E=0.10)$. An additional 54 neutral words, equated with the neutral words from Bellezza et al. on length and frequency, were included from previously published studies (e.g., Johnson et al., 2002) and were distributed equally across conditions. All the critical items were from the Bellezza et al. set.

\section{Procedure}

The general procedure in both experiments followed that in Johnson et al. (2005, Experiment 6A). The participants were (accurately) told that we were interested in the time it takes people to read words and to think about words. The participants were informed that some of the words that they would be reading would be unpleasant and were given the option not to participate.

Each trial was 6,500 msec long. On each trial, the participants saw three words presented simultaneously in a column for $1,625 \mathrm{msec}$, and they read the words aloud. After $425 \mathrm{msec}$, any one of the three words appeared again in the same location on the screen, and the participant read the word aloud again (repeat condition), or a black dot appeared that, by its location, signaled the participant to think back to and say again the word that had appeared in that location on the just-previous screen (refresh condition). The critical item was from each position equally often. For all the trials, the duration of 
the second screen was 1,450 msec, and a voice key recorded the time taken to initiate saying the critical word; responses were recorded on audiotape. The intertrial interval was $3 \mathrm{sec}$, during which time the screen was blank.

\section{Design}

For Experiment 1A, each three-item stimulus set contained one negative emotional and two neutral words (ENN). The emotional word appeared in each position equally often. In both experimental conditions (repeat and refresh), the critical word was neutral on half the trials (designated ENN_N) and emotional on half of the trials (ENN_E). Thus, the design was 2 (condition: repeat or refresh) $\times$ 2 (emotion of critical item: neutral or emotional), with trials from each combination randomly intermixed. The participants completed four 27-trial blocks, a total of 27 trials for each condition (repeat or refresh) $\times$ emotion (neutral or emotional) combination.

In Experiment 1B, for one group (50\% E), ENN stimulus sets were used for half the trials, and the other half contained all neutral words (NNN); the critical item for all the trials was neutral. As in Experiment $1 \mathrm{~A}$, the emotional word appeared in, and the critical item was taken from, each position equally often. Thus, the design was 2 (condition: repeat or refresh) $\times 2$ (set: ENN_N or NNN_N), with trials from each combination randomly intermixed. For a second group $(100 \% \mathrm{E})$, the procedure was identical, except that ENN_N sets were used for all the trials. This second group was tested after the first group in Experiment 1B in order to assess whether increasing the proportion of trials on which a negative emotional item was present would increase RTs to neutral items on refresh more than on repeat trials when negative items were never a target of refreshing. The critical trials for comparison here are those that are the same as the ENN_N trials for Group 1. As in Experiment 1A, the participants in Experiment 1B completed four 27-trial blocks.

\section{RESULTS}

We deleted trials on which RTs were less than $50 \mathrm{msec}$, the voice key was triggered by extraneous sounds (e.g., misstarts or coughs), or the critical and/or emotional item was not read correctly initially. The mean proportion of such deletions was low $(M=.03)$ and did not differ systematically across cells of the experiments. As in previous refresh studies, accuracy was high (mean proportion of errors across conditions in Experiments $1 \mathrm{~A}$ and $1 \mathrm{~B}=$ .008). RTs were calculated for correct trials only. Mean RTs for critical items are shown in Table 1, as are means for Johnson et al. (2005, Experiment 6A).

Experiment $1 \mathrm{~A}$ replicates previous findings (e.g., Johnson et al., 2002); overall, it took more time to refresh $(670 \mathrm{msec})$ than to read a word again $(526 \mathrm{msec})$. In addition, there was a condition $\times$ emotion interaction $\left[F(1,23)=9.31, M S_{\mathrm{e}}=1,076, p<.01\right]$. In reading a word again, the emotional salience of the word did not matter, but it took longer to refresh a neutral word than to refresh an emotional word, replicating the results in Johnson et al. (2005).

In Experiment 1B, in Group 1 (50\% E trials), the participants were slower on refresh than on repeat trials $\left[F(1,29)=198.79, M S_{\mathrm{e}}=1,951, p<.00001\right]$, but the effect of set and the condition $\times$ set interaction were not significant $(p \mathrm{~s}>.50)$. There was no effect of the presence or absence of a negative item in the set when emotional items were never a candidate for refreshing.
In an analysis comparing the ENN_N trials in Experiment 1A with the ENN_N trials for Group 1 in Experiment $1 \mathrm{~B}$, there was a significant experiment $\times$ condition interaction $\left[F(1,52)=16.11, M S_{\mathrm{e}}=1,109, p<.001\right]$. Subsequent analyses showed that RTs were shorter for refresh trials in Experiment 1B, where emotional items were never refreshed, than in Experiment $1 \mathrm{~A}[F(1,52)=$ 9.44, $\left.M S_{\mathrm{e}}=6,937, p<.01\right]$, and RTs did not differ for repeat trials $(p>.20)$. Likewise, when the ENN_N trials in Experiment 1A were compared with those same critical ENN_N trials for Group 2 in Experiment 1B (i.e., where both groups had an emotional item on $100 \%$ of the trials), there was a significant experiment $\times$ condition interaction $\left[F(1,42)=5.31, M S_{\mathrm{e}}=1,259, p<.05\right]$; again, RTs were shorter for refresh trials in Experiment 1B than in Experiment 1A $\left[F(1,42)=4.47, M S_{\mathrm{e}}=6,018, p<\right.$ $.05]$, but RTs did not differ for repeat trials $(p>.30)$. Importantly, a comparison of ENN_N trials for Group 1 in Experiment 1B with the corresponding ENN_N trials for Group 2 showed only a significant main effect of condition, with longer RTs for refresh than for repeat trials $\left[F(1,48)=233.94, M S_{\mathrm{e}}=1,501, p<.0001\right]$, but no main effect of group $(F<1)$ and no interaction $(F=$ 1.12). Thus, long RTs on neutral items were not simply the result of a high proportion of negative items in the experiment. In short, there was no evidence that emotional distractors disrupted the refreshing of a neutral item in Experiment 1B, where emotional items were never the target of refreshing. ${ }^{1}$

The results of Experiments $1 \mathrm{~A}$ and $1 \mathrm{~B}$ also indicate that the negative effect of an emotional distractor on refreshing, reported by Johnson et al. (2005) and replicated in Experiment $1 \mathrm{~A}$, is not due to disruption during the initial reading of the words (i.e., perceptual processing). In Experiment 1A, there was no difference in RTs to refresh critical neutral items initially presented before versus after the emotional item, $(M \mathrm{~s}=679$ and 697, respectively; $p>$ .30). Similarly, when emotional items were never critical items (Experiment 1B, Group 1), there was no difference in RTs for the refreshing of a neutral item as a function of whether or not there had been an emotional item in the set. We should emphasize that we are not suggesting that negative emotion never has an impact on perceptual processing (there is considerable evidence that under some conditions, it does; see, e.g., Most et al., 2005), only that the present results demonstrate an impact of negative emotional stimuli on one of the simplest reflective processes.

\section{DISCUSSION}

Participants are slower to refresh a neutral word than a negative emotional word from a mixed set of items and are slower to refresh a neutral word from a mixed set than from an all-neutral set. The disruption was seen on refresh, but not repeat, trials (present Experiment 1A; Johnson et al., 2005, Experiment 6A); it did not differ for neutral words initially preceded by a neutral versus an emotional word (Experiment 1A); and it was not observed when emotional 
words were never the target of refreshing, regardless of the overall amount of negative information in the experiment (Experiment 1B). Together, these findings suggest that (1) this disruptive effect of negative emotional information occurs during the reflective process of refreshing the neutral item, rather than during perceptual processing as the words are initially read (cf. Most et al., 2005; see also Pessoa \& Ungerleider, 2004), and (2) the negative impact of an emotional distractor on the refreshing of neutral items is modulated by task context or expectations. That is, we found that emotional distractors had a negative impact only when they were potentially relevant targets in the refresh task (cf. Milham et al., 2001).

How is the potentially disruptive effect of emotional stimuli on a simple process such as refreshing modulated by expectations? Expectations generated by the overall task context may affect the gain on classes of information that are potential targets of reflection. Just as in perceptual/attentional tasks, increasing the salience of a class of information could operate in a number of ways: (1) by affecting the activation of stimuli that fit that class (e.g., Cohen, Aston-Jones, \& Gilzenrat, 2004), (2) by influencing the vigilance with which stimuli are examined for potential membership in that class (e.g., Pratto \& John, 1991), or (3) by affecting the difficulty of disengaging from items from that class (Yiend \& Mathews, 2001). If activation had been greater for emotional than for neutral stimuli (Hypothesis 1), RTs should have been shorter to E items from ENN sets than to $\mathrm{N}$ items from NNN sets in Johnson et al. (2005). Although the means were in this direction (see Table 1), the difference was not significant. The effect does not appear to be due entirely to increased vigilance when emotional items might be targets (Hypothesis 2), because the participants were not slow to refresh a neutral word on any trial where an emotional item might occur and be relevant (NNN_N and ENN_N in Johnson et al., 2005), but only on trials on which an emotional item did occur and might be relevant (ENN_N). The pattern of findings across the three experiments shown in Table 1 suggests that the agenda or set created when negative emotional items were versus were not potential targets of refreshing affected how easily the participants could disengage from the emotional item when it was not selected to be refreshed (Hypothesis 3). Difficulty in disengaging could result from less effective inhibition of emotional items by selected neutral items or more effective reciprocal inhibition of neutral items by unselected emotional items, thus making RTs to refresh neutral items longer in sets in which emotional items were present. Consistent with this possibility are the results of a recent functional magnetic resonance imaging (fMRI) study with only ENN_E and ENN_N trials (Johnson et al., 2005, Experiment 6B). There was more activity in the orbitofrontal cortex, an area thought to play a role in inhibitory processes (e.g., Rule, Shimamura, \& Knight, 2002), when a neutral item was refreshed than when an emotional item was refreshed.
Johnson et al. (2005) referred to the disruptive effect of an emotional item on the refreshing of a target item as an instance of mental rubbernecking. Most et al. (2005) referred to the disruptive effect of an emotional item on the detecting of a target item as an instance of attentional rubbernecking. Of course, all cognition (perception and reflection) is mental, and attention is the engagement of cognitive processes (Johnson \& Hirst, 1993). Thus, mental or attentional rubbernecking might be equally descriptive, generic shorthand terms for the disruption of the processing of information by other, more salient information. However, as commonly used, the term attention tends to be linked to perception. Given that the distinction between perception and reflection is useful, it may be helpful to have at least two terms: attentional rubbernecking for effects during perception and mental rubbernecking for effects during reflection.

Regardless of terminology, competition from emotionally salient information may have an effect on many component processes of cognition-for example, locating or identifying stimuli, refreshing or rehearsing information, noting relations among items, and retrieving information (e.g., Johnson \& Hirst, 1993). Different perceptual and reflective processes may be differentially affected by emotion in different people. That is, individuals or groups may show different patterns of intact and disrupted control over attentional and/or mental rubbernecking, depending on the processes required by a task (Gotlib et al., 2004). Systematically exploring the impact of emotion on the component processes of more complex cognitive activities should advance our understanding of emotion-cognition interactions.

Just as perceptual/attentional tasks have been useful for exploring individual and group differences in cognitionemotion interactions (e.g., in anxiety, MacLeod \& Mathews, 1988; in posttraumatic stress disorder, Buckley, Blanchard, \& Neill, 2000; in borderline personality disorder, Posner et al., 2002), selective refreshing may be useful as well for exploring individual or group differences in the impact of emotion on more reflective processes. In particular, different patterns of outcomes depending on the task context (e.g., proportion of emotional items presented or the probability that the emotional items are targets) should provide evidence regarding whether individuals or groups differ in the relative activity levels of emotional versus neutral stimuli, vigilance to the possibility of emotional stimuli, and/or difficulty disengaging from emotional stimuli and whether there are individual differences in modulation as a function of task context.

\section{REFERENCES}

Bellezza, F. S., Greenwald, A. G., \& Banaji, M. R. (1986). Words high and low in pleasantness as rated by male and female college students. Behavior Research Methods, Instruments, \& Computers, 18, 299-303.

Botvinick, M. M., Braver, T. S., Barch, D. M., Carter, C. S., \& Cohen, J. D. (2001). Conflict monitoring and cognitive control. Psychological Review, 108, 624-652. 
Buckley, T. C., Blanchard, E. B., \& Neill, W. T. (2000). Information processing and PTSD: A review of the empirical literature. Clinical Psychology Review, 20, 1041-1065.

Burke, A., Heuer, F., \& Reisberg, D. (1992). Remembering emotional events. Memory \& Cognition, 20, 277-290.

Cahill, L., Haier, R. J., Fallon, J., Alkire, M. T., Tang, C., KEATOR, D., ET AL. (1996). Amygdala activity at encoding correlated with long-term, free recall of emotional information. Proceedings of the National Academy of Sciences, 93, 8016-8021.

Christianson, S. (1992). Remembering emotional events: Potential mechanisms. In S. Christianson (Ed.), The handbook of emotion and memory: Research and theory (pp. 307-340). Hillsdale, NJ: Erlbaum.

Cohen, J. D., Aston-Jones, G., \& Gilzenrat, M. S. (2004). A systemslevel perspective on attention and cognitive control: Guided activation, adaptive gating, conflict monitoring, and exploitation versus exploration. In M. I. Posner (Ed.), Cognitive neuroscience of attention (pp. 71-90). New York: Guilford.

Doerksen, S., \& Shimamura, A. P. (2001). Source memory enhancement for emotional words. Emotion, 1, 5-11.

Erdelyi, M. H. (1974). A new look at the new look: Perceptual defense and vigilance. Psychological Review, 81, 1-25.

Gotlib, I. H., Kasch, K. L., Traill, S., Joormann, J., Arnow, B. A., \& Johnson, S. L. (2004). Coherence and specificity of informationprocessing biases in depression and social phobia. Journal of Abnormal Psychology, 113, 386-398.

Hamann, S. (2001). Cognitive and neural mechanisms of emotional memory. Trends in Cognitive Sciences, 5, 394-400.

Johnson, M. K., \& Hirst, W. (1993). MEM: Memory subsystems as processes. In A. F. Collins, S. E. Gathercole, M. A. Conway, \& P. E. Morris (Eds.), Theories of memory (pp. 241-286). Hove, U.K.: Erlbaum.

Johnson, M. K., Nolde, S. F., \& De Leonardis, D. M. (1996). Emotional focus and source monitoring. Journal of Memory \& Language, 35, $135-156$.

Johnson, M. K., Raye, C. L., Mitchell, K. J., Greene, E. J., CunNingham, W. A., \& Sanislow, C. A. (2005). Using fMRI to investigate a component process of reflection: Prefrontal correlates of refreshing a just-activated representation. Cognitive, Affective, \& Behavioral Neuroscience, 5, 339-361.

Johnson, M. K., Reeder, J. A., Raye, C. L., \& Mitchell, K. J. (2002). Second thoughts versus second looks: An age-related deficit in reflectively refreshing just-activated information. Psychological Science, 13, 64-67.

Kensinger, E. A., Anderson, A., Growdon, J. H., \& Corkin, S. (2004). Effects of Alzheimer disease on memory for verbal emotional information. Neuropsychologia, 42, 791-800.

Kensinger, E. A., \& Corkin, S. (2003). Memory enhancement for emotional words: Are emotional words more vividly remembered than neutral words? Memory \& Cognition, 31, 1169-1180.

Koster, E. H., Crombez, G., Verschuere, B., \& De Houwer, J. (2004). Selective attention to threat in the dot probe paradigm: Differentiating vigilance and difficulty to disengage. Behaviour Research \& Therapy, 42, 1183-1192.

LABAR, K. S., \& Phelps, E. A. (1998). Arousal-mediated memory consolidation: Role of the medial temporal lobe in humans. Psychological Science, 9, 490-493.

MacLeod, C., \& Mathews, A. (1988). Anxiety and the allocation of attention to threat. Quarterly Journal of Experimental Psychology, 40A, 653-670.

Mather, M., Mitchell, K. J., Raye, C. L., Novak, D. L., Greene, E. J., \& JoHnson, M. K. (2006). Emotional arousal can impair feature binding in working memory. Journal of Cognitive Neuroscience, 18, 614-625.

Mathews, A. M., \& MacLeod, C. (1994). Cognitive approaches to emotion and emotional disorders. Annual Review of Psychology, 45, 25-50.

McKenna, F. P., \& Sharma, D. (2004). Reversing the emotional Stroop effect reveals that it is not what it seems: The role of fast and slow components. Journal of Experimental Psychology: Learning, Memory, \& Cognition, 30, 382-392.

Milham, M. P., Banich, M. T., Webb, A., Barad, V., Cohen, N. J., WszaleK, T., \& Kramer, A. F. (2001). The relative involvement of anterior cingulate and prefrontal cortex in attentional control depends on nature of conflict. Cognitive Brain Research, 12, 467-473.

Most, S. B., Chun, M. M., Widders, D. M., \& ZALd, D. H. (2005). Attentional rubbernecking: Cognitive control and personality in emotioninduced blindness. Psychonomic Bulletin \& Review, 12, 654-661.

Niedenthal, P., \& Kitayama, S. (Eds.) (1994). The heart's eye: Emotional influences in perception and attention. San Diego: Academic Press.

Nolen-Hoeksema, S. (2000). The role of rumination in depressive disorders and mixed anxiety/depressive symptoms. Journal of Abnormal Psychology, 109, 504-511.

Pessoa, L., \& Ungerleider, L. G. (2004). Neuroimaging studies of attention and the processing of emotion-laden stimuli. Progress in Brain Research, 144, 171-182.

Posner, M. I., Rothbart, M. K., Vizueta, N., Levy, K. N., Evans, D. E., Thomas, K. M., \& Clarkin, J. F. (2002). Attentional mechanisms of borderline personality disorder. Proceedings of the National Academy of Sciences, 99, 16366-16370.

Pratto, F., \& John, O. P. (1991). Automatic vigilance: The attentiongrabbing power of negative social information. Journal of Personality \& Social Psychology, 61, 380-391.

Raye, C. L., Johnson, M. K., Mitchell, K. J., Greene, E. J., \& Johnson, M. R. (in press). Refreshing: A minimal executive function. Cortex.

Raye, C. L., Johnson, M. K., Mitchell, K. J., Reeder, J. A., \& GreEne, E. J. (2002). Neuroimaging a single thought: Dorsolateral PFC activity associated with refreshing just-activated information. NeuroImage, 15, 447-453.

Reisberg, D., \& Hertel, P. (Eds.) (2004). Memory and emotion. New York: Oxford University Press.

Rule, R. R., Shimamura, A. P., \& Knight, R. T. (2002). Orbitofrontal cortex and dynamic filtering of emotional stimuli. Cognitive, Affective, \& Behavioral Neuroscience, 2, 264-270.

SPERLING, G. (1960). The information available in brief visual presentations. Psychological Monographs, 74, 1-29.

Strange, B. A., Hurlemann, R., \& Dolan, R. J. (2003). An emotioninduced retrograde amnesia in humans is amygdala- and beta-adrenergicdependent. Proceedings of the National Academy of Sciences, 100, 13626-13631.

Yiend, J., \& Mathews, A. (2001). Anxiety and attention to threatening pictures. Quarterly Journal of Experimental Psychology, 54A, $665-681$

\section{NOTES}

1.Two analyses compared conditions common to Johnson et al. (2005, Experiment 6A) and Experiments 1A and 1B. In an analysis including conditions ENN_E and ENN_N from Experiment 1A and Johnson et al. (2005), there were no effects of experiment. When emotional items were potential refresh targets, the participants were slower by the same amount in the refreshing of neutral items, in comparison with emotional items (42 and $48 \mathrm{msec}$ in Experiment 1A and Johnson et al., 2005, respectively), and there was no effect of emotion on repeat trials. In an analysis including conditions that were the same in Group 1 in Experiment $1 \mathrm{~B}$ and Johnson et al. (NNN_N and ENN_N), there was a three-way interaction [experiment $\times$ set $\times$ condition, $F(1,51)=4.40, M S_{\mathrm{e}}=534.56$, $p<.04$ ], reflecting that neutral items were slower to be refreshed when presented in the context of an emotional item when the emotional items were candidates for refreshing, but not when they were not possible candidates. Of course, there may be individual or group differences in the likelihood that task-irrelevant emotional information is, nevertheless, distracting. Thus, there are potentially separable effects across individuals or groups of facilitated processing of emotional items, disruption on neutral items from task-irrelevant emotional items, and disruption on neutral items from emotional items that are potentially task relevant. This is a potentially interesting direction for future research.

(Manuscript received July 14, 2005; accepted for publication November 15, 2005.) 